\title{
Notas para o estudo das "Tinhas"
}

\author{
Pelo Dr. Floriano de Almeida \\ Trabalho do Laboratorio de Microbio- \\ logia da Fác. de Medic. de S. Paulo
}

$\boldsymbol{R}_{\text {EUNINDO, nas linhas abaixo, alguns dados clinicos } \mathbf{e}}$ $\boldsymbol{R}$ mycologicos sobre as "tinhas", procuramos contribuir, embora ligeiramente, para o diagnostico dessas mycoses.

As "tinhas" são produzidas por um sem numero de cogumelos que atacam ora a pelle ora seus annexos, como pellos e unhas. No quadro que se segue classificamos as "tinhas" de accordo com sua localisação e cogumelos responsaveis. Assignalaremos, á medida que considerarmos cada uma dellas, as que atacam tambem as unhas.

Além das tinhas ennumeradas no quadro muitas outras existem, como as chamadas tinhas chromogenas, cujos agentes pathogenicos não estão ainda bem estudados. Estas tinhas relativamente frequentes em determinadas regiões da America Central e da parte septentrional da America do Sul, recebem denominações variadissimas consoante o paiz em que são endemicas. 'E' assim que encontramos as denominações de Mal de Pinta, Carate, Cute, Cativi, Quirica, PurúPurú e um sem numero de outras que fastidioso seria referir.

Na litteratura scientifica recebem a denominação de carates e se caracterisam por variedades de accordo com a coloração apresentada. Chevarria e Shipley, em um optimo trabalho sobre o assumpto, consideram 5 variedades a saber: branca, negra, violeta, azul e vermelha. Segundo descripção desses autores o carate é uma dermatomycose caracterisada por prurido, coloração ou descoloração da pelle acompanhada sempre de descamação. Ataca de preferencia as partes descobertas. 0 exame microscopico das escamas tratadas pela potassa a $40 \%$ e a quente, permitte, ás vezes, encontrar filamentos mycelianos. As culturas são 
obtidas, segundo esses mesmos autores, semeando escamas nos meios de Sabouraud.

鄯

$\stackrel{ن}{*}$

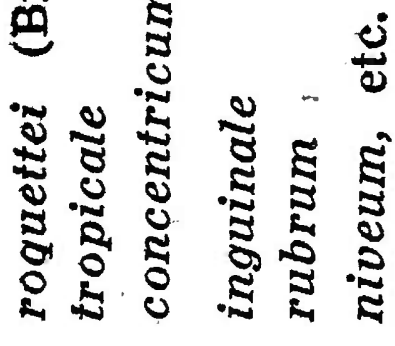

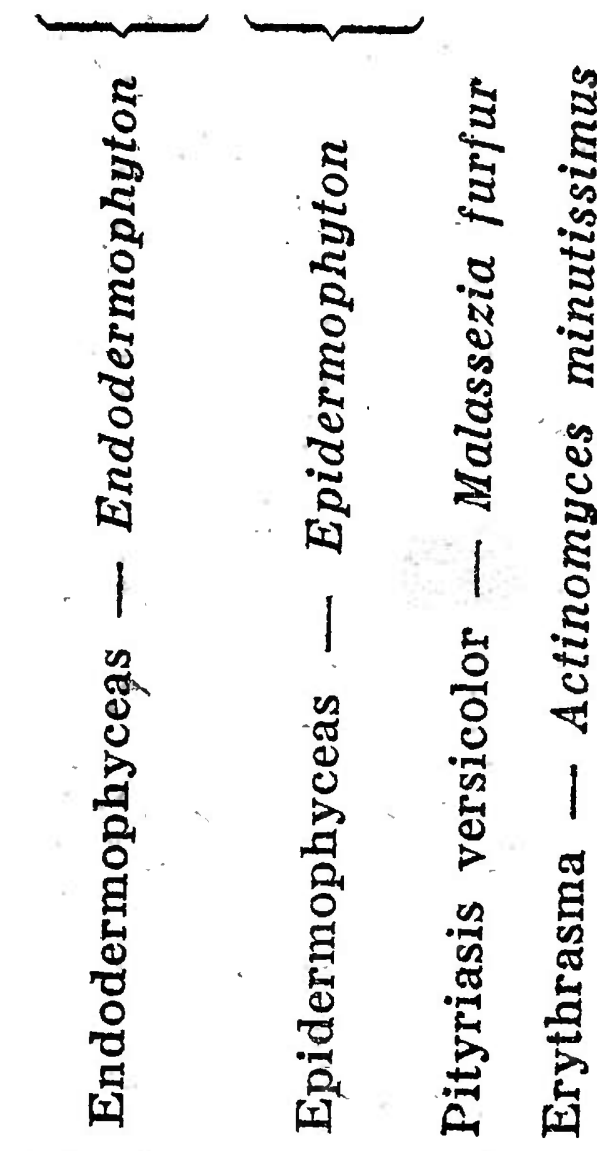

$\stackrel{\square}{\circ}$

离

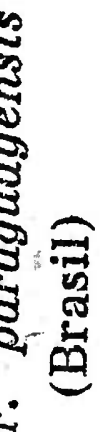

ติ

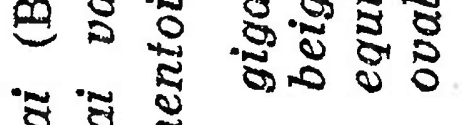

$\tilde{z} \tilde{z}$

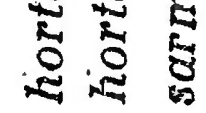

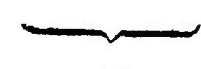

$\frac{0}{3}$

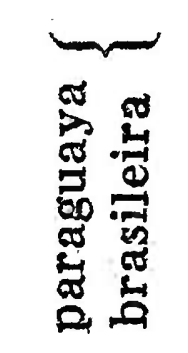

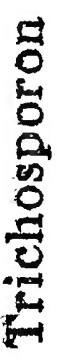
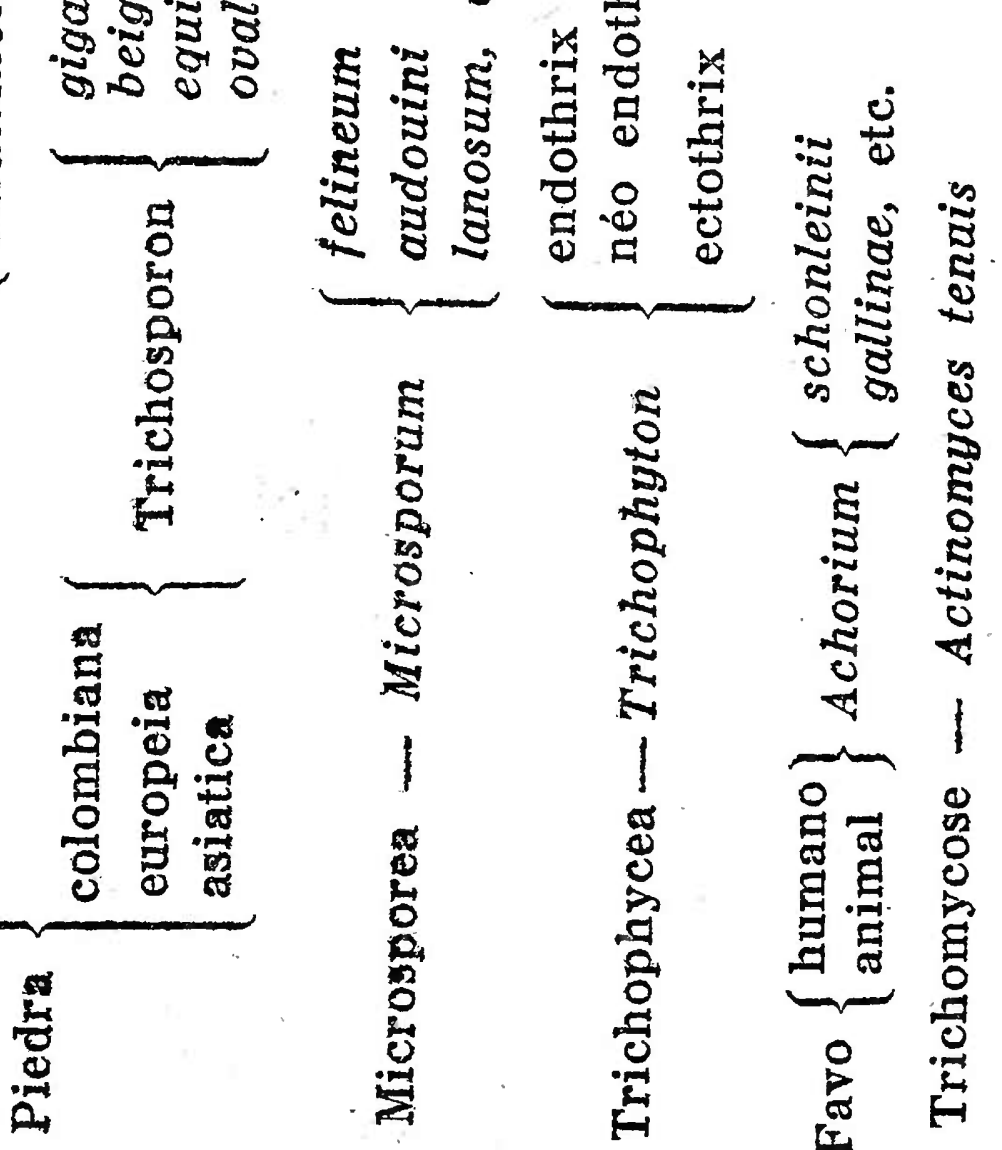

$E$
$\vdots$
0
0
0
0
0
0
0
0
0

1

告

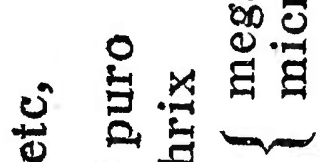

.

s.

记

象

凪
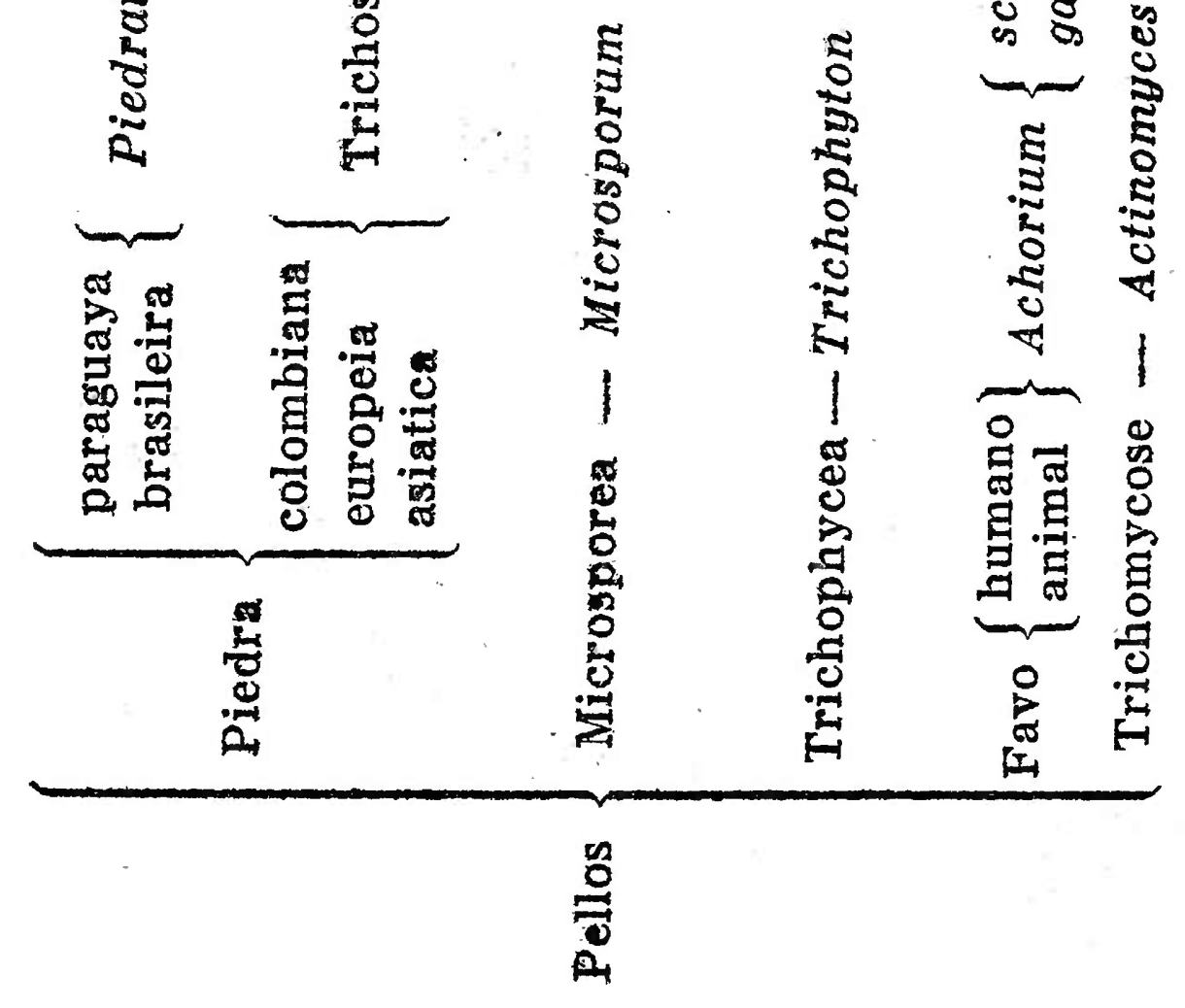

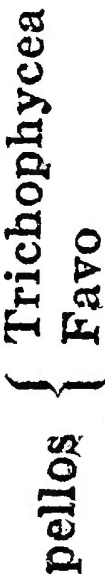

0

... 
Passemos porém ao estudo do quadro começando pelas

\section{ENDODERMOPHYCEAS}

São dermatoses pouco conhecidas no Brasil por serem peculiares a certas regiões da Oceania e Asia, principalmente as ilhas do Archipelago de Tokelau, originandose dahi a denominação de Tokelau para designar essa mycose.

Esta dermatose foi estutada no Brasil pela primeira vez por 0 . da Fonseca, em um indio Purú-borá das margens do Rio São Miguel, affluente do Guaporé, na fronteira de Matto Grosso e Bolivia.

As endodermophyceas se caracterisam pelo apparecimento de placas largas, circinadas, achromicas e egualmente escamosas em toda sua extensão. São lesões esparsas pelo corpo mas com predilecção pelo tronco e face.

0 parasito é encontrado nas escamas e perfeitamente visivel ao microscopio, entre lamina e laminula, depois de clareada a escama pela potassa a $40 \%$ ou lactophenol de Amann ou o chlorolactophenol.

Para melhor se fazer a penetração do liquido clareador, aquece-se ligeiramente a lamina, aquecimento este que eliminará as bolhas de ar existentes no material. Uma vez verificada a presença de cogumelo sob a forma de filamentos mycelianos septados e ramificados, deveremos então semear as escamas em meios mycologicos apropriados, como os de prova de Sabouraud.

Não sendo possivel a sementeira immediata, conservam-se as escamas entre duas laminas flambadas e resfriadas, tendo o cuidado de annotar o nome do doente e a data, e remetter o material ao laboratorio. Esse material se conserva durante algum tempo em bôas condições.

\section{EPIDERMOPHYCEAS}

Esta dermatose ataca qualquer região do corpo humano, apresenta, porém, accentuada predilecção pelas dobras ou pregas da virilha, axilla, sulco inter-gluteo, sulco mammario (nas mulheres) e espaços inter-digitaes.

Clinicamente se caracterisa pelo apparecimento de placas erythematosas, escamosas, principalmente nos bordos. Estas lesões são muito semelhantes ás apresentadas pela trichophycea da pelle glabra, sendo bastante difficil estabe- 
lecer um diagnostico sem o concurso do laboratorio. Além das lesões da pelle, podem os Epidermophytons determinar lesões nas unhas.

Varias especies podem produzir esta mycose e, dentre ellas, têm sido encontradas entre nós as seguintes: $E$. inguinale, $E$. rubrum, E. niveum, $E$. interdigitale.

Da mesma maneira que para as Endodermophyceas, o parasito deve ser pesquizado nas escamas, usando-se a mesma technica já exposta.

\section{PITYRIASIS VERSICOLOR}

A pityriasis se localisa de preferencia na parte superior do tronco, dahi se extendendo ao pescoço e em certos casos ao rosto. Suas lesões são tambem constituidas por placas dyschromicas, de onde pela raspagem se destacam minusculas escamas que raramente ultrapassam um millimetro de diametro.

O exame miscrocopico destas escamas revela geralmente uma abundancia de pequenos mycelios e grande numero de esporos, facto este muito caracteristico.

As culturas, apesar das numerosas tentativas, têm resultado mais ou menos negativas, não obstante a abundancia do cogumelo, Malassezia furfur.

\section{ERYTHRASMA}

Como as precedentes esta mycose se caracterisa pela formação de placas limitadas, erythematosas e tambem recobertas de escamas. Tem como localisações principaes as virilhas, a aprte superior da face interna das coxas e regióes escrotal e axillar. $O$ agente etiologico do erythrasma é o Actinomyces minutissimus ainda não cultivado satisfactoriamente.

\section{PIEDRA}

Examinemos agora as tinhas dos pellos começando pela Piedra ou trichomycose nodular ou ainda trichosporia. 0 diagnostico clinico desta mycose é extremamente facil, pois é sufficiente vêr os pequenos nodulos de coloração negra ou 
esbranquiçada que em grande numero se encontram nos cabellos parasitados ou nos pellos da barba, bigode, axilla ou pubis. Relativamente pequenos, esses nodulos attingem até um millimetro de diametro e quando bastante desenvolvidos circumdam o pello que parasitam, formando-lhe uma bainha. São de consistencia dura e fortemente adherentes, dando a sensação, pela passagem do pente, de pequeninas pedras, derivando desse facto a denominação popular de "piedra" que lhe foi dada na Colombia. Vista pela primeira vez na Europa, essa mycose só foi porém bem conhecida depois das observações dos casos colombianos, que forneceram abundante material aos especialistas europeus.

No Brasil foram tambem estudados numerosos casos de piedra, chegando 0 . da Fonseca e Arêa Leão a separar a forma brasileira, da colombiana e europea, creando o novo genero Piedraia em contraposição ao antigo Trichosporon.

Conhecem-se hoje, portanto, dois generos de cogumelos causadores dessa mycose e nelles têm sido descriptas varias especies, como se pode vêr no quadro numero $\mathrm{I}$.

Pelo exame microscopico dos pellos parasitados e tratados da mesma maneira que as escamas pelos mesmos liquidos clareadores, veremos que os nodulos são constituidos por filamentos septados que formam cellulas mais ou menos quadrangulares. Nesses nodulos, no genero Piedraia, encontramos ainda certas formações kysticas muito bem descriptas por Parreiras Horta e não descriptas no genero Trichosporon. Além desta differença microscopica, ha outra que é a da côr, geralmente preta nos nodulos dos casos brasileiros produzidos pela Piedraia hortai e esbranquiçada nos casos produzidos pela especie Trichosporon giganteum ou outra.

Para a obtenção de culturas nada mais temos a fazer que cortar o pello parasitado em pequenos pedaços que contenham um ou mais nodulos e tratal-os pelo ether durante a 2 minutos e em seguida semeiar nos meios de prova de Sabouraud. O desenvolvimento do cogumelo se inicia alguns dias mais tarde, sendo as colonias pretas e conferindo uma tonalidade escura ao meio, nos casos de Piedraia
hortai.

As culturas deste germen são duras, seccas e fortemente adherentes ao meio e claras, rugosas, ás vezes humidas nos casos de Trichosporon. 


\section{MICROSPOREA}

A microsporea como a trichophycea determina a queda dos cabellos parasitados dando logar á formação de placas depiladas, - por esse facto ambas recebem a denominação de tinhas tonsurantes.

São mycoses peculiares á infancia, principalmente á edade escolar, desapparecendo quasi sempre na puberdade. São caracterizadas clinicamente por placas tonsurantes e o simples exame dessa manifestação já nos permitte encaminhar o diagnostico para uma dessas tinhas. E' assim que a microsporea apresenta quasi sempre poucas placas (uma a tres), largas, redondas, regulares, inteiramente depiladas, recobertas de escamas. Os pellos são cortados rente, alguns millimetros acima da superficie do couro cabelludo e são cobertos por uma bainha de esporos esbranquiçados, dando ás placas o aspecto de terem sido cobertas por uma camada de cinza clara. O exame microscopico dos pellos parasitados, mostra-os claramente envolvidos pelos esporos. No interior do pello observam-se, em alguns casos, filamentos mycelianos situados abaixo da cuticula.

Em certos casos de microsporeas encontram-se manchas dischromicas na porção superior do tronco, no pescoço e na face.

A obtenção das culturas é realisada pela sementeira dos pellos nos meios de Sabouraud. Além do homem as microsporeas são encontradas frequentemente nos animaes domesticos, gato, cão, etc. Das varias especies de Microsporum encontrados, apenas o M. audouini é peculiar ao homem, sendo o $M$. felineum, $M$. lanosum, etc., especies de animaes e tambem parasitam o homem.

\section{TRICHOPHYCEA}

Como a precedente esta determina no homem e em outros animaes, placas de tonsura. As affecções do adulto são, porém, differentes das observadas na creança. E' assim que na infancia a trichophycea se caracterisa pelo apparecimento de numerosas placas de tonsura, do couro cabelludo, placas essas escamosas, amarelladas, pequenas e irregulares. Dentre as escamas emergem pellos parasitados ou não, os primeiros cortados a poucos millimetros de sua 
sahida e os segundos longos e intactos. Essas pequenas placas apparecem em certos casos em numero de muitas dezenas. Na maioria dos casos de trichophyceas ha lesões da pelle glabra circumvisinha. $O$ pello parasitado, arrancado e examinado segundo a technica já exposta, permitte verificar a estructura do parasito, que é essencialmente monomorpha e facilmente reconhecivel. Os Trichophytos são representados por filamentos mycelianos compostos de articulos curtos, pouco mais longos que largos, reunidos em cadeias. De accordo com a disposição dos mycelios e esporos nos cabellos, Sabouraud estabeleceu para estes cogumelos a classificação seguinte:

$$
\text { Trichophyton }\left\{\begin{array}{l}
10^{\circ}-\text { endothrix puro } \\
20^{\circ}-\text { néo-endothrix } \\
30^{\circ} \text { - ectothrix }\left\{\begin{array}{l}
\text { microides } \\
\text { megasporos }
\end{array}\right.
\end{array}\right.
$$

Nos primeiros, endothrix, o parasito se mostra no interior do pello sob a forma de filamentos longos constituidos por cellulas quadrangulares.

Nos néo-endothrix, encontram-se cabellos tendo não só filamentos no interior como outros muitos no exterior, em via de penetração.

Os ectothrix, apresentam além de filamentos ou cadeia de esporos no interior, apenas nas camadas superficiaes, uma grossa bainha externa de filamentos mycelianos e esporos. Estes ultimos dispostos tambem em cadeias parallelas entre si e acompanhando a direcção do pello. Os esporos podem ainda variar quanto ao tamanho, dando então uma subdivisão, isto é, Trichophytons ectothrix microides (esporos pequenos) ou megasporos (esporos grandes).

(Não sendo nossa intenção entrar em particularidades acerca de cada uma dessas variedades acima expostas, recommendamos, aos que desejarem esclarecimentos completos neste assumpto, que recorram ao tratado Les teignes de
Sabouraud).

Vimos as lesões de Trichophycea da infancia em que o cogumelo ataca apenas o cabello. No adulto apparecem lesões dos pellos da barba, das unhas e da pelle glabra e não mais nos cabellos. Nos pellos da barba as lesões trichophyticas se caracterisam por serem inflammatorias, elevadas, cobertas de crostas, formadas pelo pús sahido dos folliculos pillosos. Nessas crostas os pellos são geralmente com 
Quando constituida por nodulos suppurativos isolados a trichophycea é denominada sycosis. No caso de se conglomerarem os nodulos temos o Keryon. Estas lesões suppurativas podem tambem ser encontradas no couro cabelludo da creança.

Além das lesões dos pellos, no adulto, os Trychophytons atacam a pelle glabra determinando alterações clinicamente muito semelhantes ás do herpes circinado, isto é, lesões que se manifestam por placas erythematosas, escamosas, de bordos arredondados, circinados e não raro vesiculosos. 0 parasito é com mais facilidade encontrado nas escamas da peripheria das placas.

Nas unhas determinam uma onychomycose, caracterisada pelo espessamento da porção situada abaixo da taboa interna, dando-lhe o aspecto de medulla de sabugueiro. 0 parasito é ahi facilmente encontrado, bastando raspar a porção da unha affectada e examinal-a, como se fosse uma escama.

\section{FAVO}

Outra tinha de diagnostico clinico relativamente simples e facil é o favo ou tinha favosa. Não é como as tonsurantes peculiar á infancia e nem desapparece com a puberdade. E' ao contrario uma mycose que adquirida na infancia e não tratada convenientemente, acompanha o individuo durante quasi toda sua vida.

As tonsurantes atacam o pello e cortam-no; o favo ataca o pello e mata-o. Determina assim uma alopecia, ás vezes, sem cura. Para o diagnostico da tinha favosa, dois elementos existem que nunca faltam, e que são: o pello parasitado e o godêt. o pello parasitado é caracteristico, tem a resistencia quasi totalmente perdida sendo destacado facilmente, e apresenta-se sem a côr natural, tornando-se acinzentado, sem brilho e além disso torcido. $O$ bulbo pilloso é atacado tambem, razão pela qual o cabello morre e se destaca dando logar a alopecias ás vezes incuraveis. 0 segundo elemento que nunca falta no favo é o godêt (gallicismo já consagrado pelo uso, para o qual não se tem uma traducção adequada), caracterisado pelo accumulo de filamentos em torno de um pello, filamentos esses que se encaminham para o bulbo e dão então logar á formação de uma elevação circular com uma excavação central de onde emerge o pello doente. 
Quando o parisitismo é muito accentuado os godêts pela abundancia e coalescencia podem se adelgaçar e transformar-se em escamas paśsando o favo, de typico, a se assemelhar ao favo pityroide ou favo escamoso.

o exame microscopico do pello demonstra em seu interior a existencia de filamentos mycelianos, esporos e numerosas bolhas de ar.

Os filamentos, pouco numerosos, são longos e ramificados, outras vezes curtos e muito ramificados constituindo então os chamados tarsos favicos. O godêt, macroscopicamente reconhecivel, não necessita de exame microscopico para seu diagnostico.

Além das lesões dos pellos o favo determina lesões escamosas da pelle glabra, constituindo, como já dissemos, o favo pityroide. O favo além de lesões humanas dá tambem lesões em animaes inferiores principalmente nas aves, como a gallinha. $\mathrm{O}$ favo das gallinhas pode se manifestar tambem no homem. Como parasito do favo temos o genero Achorium com varias especies, entre ellas a schönleinii ou humana e a gallinae ou das gallinhas.

Uma ultima mycose tambem localisada nos pellos é a

\section{TRICHOMYCOSE AXILLAR ou INGUINO CRURAL}

Relativamente commum e universalmente conhecida, determina nos pellos axillares ou pubianos o apparecimento de nodulos irregulares pouco adherentes e não muito volumosos, ás vezes constituindo uma especie de bainha irregular de côr amarella, vermelha ou preta, onde encontramos finissimos filamentos mycelianos do parasito, que é o Acti-
nomyces tenuis.

A côr preta ou vermelha é dada pela associação de coccos chromogenos. O $A$. tenuis não determina a queda dos pellos e seu parasitismo é inoffensivo, desapparecendo com relativa facilidade. As culturas, durante muito tempo em gelose-sangue, gelose-ascite conseguidas, principalmente em gelose-sangue, gelose-ascite ou gelose-urina.

De conformidade com a pigmentação apresentada distinguem os autores tres variedades de trichomycose axillar, a saber: a flava, nigra e rubra. O pigmento negro e vergumelo é, segundo numerosos autores, independente do cogumelo sendo produzido por bacterias associadas. 
Com a Trichomycose axillar terminamos o estudo ligeiro que vimos fazendo dos cogumelos productores de tinhas.

Resumindo, podemos dizer que as tinhas são mycoses que determinam além de lesões escamosas na pelle, lesões outras em seus annexos, pellos e unhas.

0 estudo do parasito nas escamas se faz entre lamina e laminula depois de convenientemente clareado o material pelos clareadores communs mycologicos, potassa a $40 \%$, lactophenol e chlorolactophenol, a quente.

Os pellos são tambem clareados pelos mesmos processos que as escamas.

As culturas são obtidas semeando o material parasitado, escama ou pello ou unha nos meios mycologicos (meios de prova maltosado ou glycosado de Sabouraud).

Os caracteres culturaes permittirão a identificação do germen.

Era nosso intuito tratar tambem de outras mycoses, porém, achamos mais pratico dividir o assumpto em duas partes, nos referindo agora apenas ás tinhas, deixando para outra opportunidade as restantes mycoses. 